\title{
О СОСТАВЛЕНИИ УЧЕБНИКА РУССКО-СЛОВАЦКИХ ОМОНИМОВ
}

\author{
Лукаш Гаярски
}

\section{ABOUT THE COMPILATION OF THE RUSSIAN-SLOVAK HOMONY TEXTBOOK}

\begin{abstract}
Lukáš Gajarský
Резюме: Межъязыковые омонимы - это слова, имеющие одинаковую или сходную фонетическую, графическую форму, но различное значение. В нашем случае это русские и словацкие пары слов, которые формально полностью или частично идентичны, но отличаются по своему значению. Эти слова нередко являются причиной неверного толкования, поэтому их называют «ложными друзьями переводчика». Следовательно, межъязыковые омонимы - частый источник межъязыковой интерференции. Данная статья посвящена составлению учебника русско-словацких омонимов для словацких студентов в вузах, задачей которого является не только освоение новой лексики, но и недопущение негативного трансфера данных единиц как родным, так и русским языком.
\end{abstract}

Ключевые слова: омонимия, межъязыковые омонимы, интерференция, упражнения для устранения интерференции

\begin{abstract}
Interlingual homonyms are words that have the same or similar phonetic or graphic form, but have different meanings. In this case, it is Russian and Slovak pairs of words that are formally completely or partially identical, but differ in meaning. These words are often the cause of misinterpretation, and that is why they are called "false friends of the translator." For this reason, interlingual homonyms are a frequent source of interlingual interference. The paper is devoted to compiling a textbook of Russian-Slovak homonyms for Slovak students studying Russian language at universities. The aim of the textbook is not only to master the new vocabulary, but above all to prevent a negative transfer between their mother tongue and Russian.
\end{abstract}

Key words: homonymy, interlingual homonyms, interference, anti-interference exercises

DOI: $10.14712 / 9788076032088.3$

Межъязыковая интерференция - это перенесение элементов из одной языковой системы в другую на основании их формального (графического или звукового), грамматического, но и нередко семантического сходства. Этот трансфер может быть как позитивным, в случае когда сходство облегчает понимание и освоение иностранного языка, так и негативным - когда схожесть ведет к ложной идентификации, нарушению нормы и ошибкам. Данный процесс происходит в условиях двуязычия, складывающегося либо при языковых контактах, либо при индивидуальном изучении иностранного языка. Межъязыковая интерференция выражается в отклонениях от нормы и системы иностранного языка под влиянием родного. Чаще всего межъязыковую интерференцию рассматривают как отрицательное явление, так как из-за нее возникает недопонимание между говорящими, она замедляет процесс коммуникации, создает определенные трудности как в повседневном разговоре, так и в бизнес-общении. Согласно X. Брауну, большинство ошибок в иностранном языке возникает в результате догадок студента, что форма в иностранном языке тождественна или подобна форме родного языка. Студент, который 
еще полностью не владеет правилами иностранного языка, применяет в своей передаче иностранного языка правила родного языка $(2014,160)$. Интерференция проявляется на всех уровнях владения иностранным языком. Браун подчеркивает, что на низшем уровне владения иностранным языком превалирует интерлинвальный трансфер, но после того, как студент начнет осваивать формы и структуры иностранной системы, возникает все больше и больше ошибок как следствие генерализации в рамках иностранного языка $(2014,162)$. Поэтому в лингвистическом сообществе бытует мнение, что избежать межъязыковой интерференции практически невозможно.

Межъязыковые омонимы «опасны» как для студентов, начинающих изучать язык, так и для опытных переводчиков, которые также допускают ошибки при переводе. Это случается потому, что переводчики уверены в своих знаниях и не проверяют значение слов в словарях.

Чем родственнее языки, тем большая вероятность переноса элементов в этих языковых системах. Если разница между языками больше, они не являются генетически родственными, то случаев автоматической передачи будет намного меньше.

Й. Филипец и Ф. Чермак объясняют происхождение омонимии так: «одна лингвистическая форма (морфема, слово, фраза, предложение), написанная или произнесенная, имеет две или более функции, значения, которые не связаны друг с другом. Различают омонимию собственную (в форме одной лексемы) и несобственную (в форме разных лексем); грамматическую, которая носит системный характер, и лексическую, довольно маргинальную». Эти авторы подчеркивают тот факт, что омонимия встречается только в изолированных языковых формах, но в более широком контексте эта „асимметрия формы и функции (значения)“ исчезает, за исключением, конечно, случаев сознательной двусмысленности и игры слов, с которыми мы сталкиваемся в художественных текстах и веселых интервью» (Филипец, Чермак, 1985, 141).

Таким образом, «омонимы являются проявлением смысловой неоднозначности, то есть неясности, двусмысленности, которая тесно связана с многозначностью (полисемией) слов» (Ондрус, Горецки, Фурдик, 1980, 168).

Как известно, омонимы могут быть результатом случайного звукового совпадения, но для славянских языков весьма интересны исторически закономерные межъязыковые фонетические параллели. Пристальное внимание к межъязыковой омонимии в обучении русскому языку для носителей словацкого языка весьма актуально.

Современные исследования убедительно показывают лексическую близость славянских языков, причем не только в пределах традиционных восточнославянских, южнославянских и западнославянских континуумов (Кретов, 2015), но и отдельных славянских языков разных генетических характеристик. Безусловно, это определяется близостью общего лексического фонда славянских языков. По мнению Н.А. Кондрашова, в современных славянских языках «четверть активного запаса унаследована от праславянской эпохи» (Кондрашов, Кубик, 1977, 189).

«Межъязыковая омонимия наиболее выражена в той области лексики, которая восходит к старославянскому словарному запасу, особенно к базовому лексическому фонду. Речь идет о случаях, когда исконно одно слово в процессе развития было разложено на такие значения, между которыми в речевой практике с синхронной точки зрения не ощущается никакой связи. В лексикологии этот тип отношений между словами обычно называют межъязыковой гомогенной омонимией (Ванько, 2004, 62). Важно отметить, что пристальное внимание следует уделять главным образом лексемам, в которых моносемантизм постепенно переходит в полисемантизм, а первоначальное значение сохраняется в другом языке (Ванько, 2004, 64). 
Именно благодаря этим межъязыковым гомогенным омонимам мы можем разделить их на основе их «полисемантических пар, которые идентичны по смыслу, но отличаются не коррелятивными метафорическими лексико-семантическими связями, специфическими функционально-стилистическими особенностями и связностью» (Ванько, 2004, 65). Сюда также включаются пары, которые являются либо моносемантическими, либо, во втором случае, полисемантическими. Это свидетельствует о том, что их значения чаще всего метафоричны (Ванько, 2004, 65). «Менее многочисленную группу представляют гетерогенные межъязыковые омонимы, которые вычленяются по большей части на основе несовместимости денотатов. Прежде всего сюда относят окказиональную межъязыковую омонимию, при которой различные по происхождению лексемы случайно уравниваются в своей форме или же их формальная тождественность обусловлена регулярными фонетическими процессами в одном из сравниваемых языков» (там же, 69).

Исходные и сохранившиеся общие черты лексических систем определяют актуальность сопоставительного изучения лексики словацкого и русского языков. При этом наибольший интерес представляют русско-словацкие межъязыковые омонимы как сравнительная лексическая категория, в которой выражаются отношения между двумя лексемами с эквивалентной формой и неэквивалентным содержанием.

С явлением межъязыковой интерференции при работе с омонимами мы регулярно сталкиваемся не только у студентов, для которых словацкий является родным, но и у носителей русского языка, долгое время живущих в Словакии. Речь идет о занятиях по практическому языку, лексикологии, деловому и художественному переводу. Тренировочные упражнения для освоения межъязыковой омонимии появляются в разных учебниках время от времени, но комплексного материала для обучения межъязыковым русско-словацким омонимам не хватало, поэтому мы решили восполнить этот пробел. Над публикацией Учебник русскословацких омонимов работали автор данной статьи и доцент Татьяна Григорьянова.

На начальном этапе планирования учебника необходимо было ответить на основные вопросы, а именно: Кто будет использовать этот учебник? (Кому будет адресован?), Каков будет его объем и глубина материала? Какая ставится цель? Ответив на эти вопросы, мы продолжили работу над учебником, причем каждый шаг многократно тестировался непосредственно в аудитории. Учебник адресован в первую очередь студентам кафедр русистики, или же студентам, которые владеют русским языком минимум на уровне В1 и желают углубить свои познания в области русско-словацкой межъязыковой омонимии.

Для учебника межъязыковых омонимов основным критерием выбора слов была их одинаковая или похожая фонетическая форма с разными значениями, то есть те русские и словацкие пары слов, которые в своей исходной форме формально полностью или частично идентичны, но различаются по своему значению - следовательно, согласно терминологии Ф. Чермака речь идет об омонимии собственной. В учебник были включены только те пары слов, которые принадлежат к одной и той же части речи (за исключением нескольких случаев).

По объему книга разделена на 12 глав. Одним из наиболее важных вопросов был сколько новых омонимов будет включать одна лекция. Поскольку каждый аспект учебника несколько раз тестировался на практике, основываясь на опыте, оптимальным количеством новых омонимов в одной лекции было 25 единиц. При меньшем количестве единиц потенциал студентов не реализовывался полностью, при большем - у студентов наблюдались проблемы с надстандартным объемом языкового материала. Таким образом, учебник содержит упражнения с 300 русско-словацкими межъязыковыми омонимами. 
Как мы уже упоминали, важным вопросом при составлении учебника был не только количественный аспект (количество единиц), но и качественный, а именно - глубина. Для многозначных слов даны не все дифференциальные значения, а только те, которые относятся к активной лексике. Не приводится профессиональная лексика, как например бабка: 1. «надкопытный сустав ноги у животных»; 2. «часть металлического станка», а также диалектные выражения: рус. бабка в значении «несколько снопов в поле», слов. бабка в значении «часть патентной застежки», «наковальня для ковки кос» (Кузнецов, 2014).

В следующей части данной статьи мы представим различные типы упражнений, которые включают отдельные лекции. Каждая глава построена так, чтобы конкретные омонимы повторялись, но при этом сложность упражнений постепенно нарастала. Из-за ограниченного пространства мы продемонстрируем концепцию учебника на примере пяти омонимов.

Каждая лекция начинается с текста, содержащего 25 омонимов, которые будут отработаны в этой главе. В начале мы выбрали 300 самых частотных омонимов и упорядочили их в алфавитном порядке. Этот алфавитный порядок мы старались сохранить на протяжении всего учебника. Одна лекция состоит, например, из этих омонимов: научный, поток, почётный, праздный, превратить, предавать, предварить, предложить, преломиться, прельстить, пресекать, пресный, прибрать, привесок, привстать, приговор, прием, приёмны, прикрыть, приправа, приспеть, пристать, притулиться, провизия, пруд.

Все тексты в данной книге оригинальны. Создать целостный и увлекательный текст было задачей не из легких, так как в нашем случае нельзя было пользоваться уже существующими текстами из иных источников.

Каждая лекция начинается главным текстом и вопросами к нему. Контекст очень важен. Именно он помогает осознать отличия в двух языковых системах и далее, таким образом, устранить негативную передачу.

\section{1. Прочитайте текст:}

\section{Каникулы у бабушки}

Наконец наступили каникулы, и моя семья решила отправиться на две недели к бабушке, которая живет в деревне недалеко от нашего города. Когда мы туда добрались, бабушка встречала нас у ворот, махая рукой, и, как всегда, улыбаясь. Бабушкин верный пес вилял хвостом, приветствуя нас. На кухне, где она угощала нас вкусным ужином, были стулья и диван. На полке стояла ваза с фруктами.

В текст можно было внести фразу «ваза с цветами», но учитывая совпадение значений в русском и словацком языках (ваза с цветами = váza $s$ kvetmi), это нам показалось нецелесообразным. Словосочетание «ваза с фруктами» нельзя перевести как váza s ovocím, потому что оно бессмысленно в словацком языке. Каждый вводный текст включает приблизительно 500 слов, поэтому при нескольких омонимах реализуются их различные значения.

Следующий вид упражнений - соединение лексемы с ее значением. Для естественных языков характерно, что отношение между формой и значением слова не является симметричным, т.е. одной форме соответствует один контекст. Напротив, большинство слов в языке многозначны. Это означает, что одной форме соответствует несколько смыслов. Именно эта асимметричная связь между содержанием и формой предполагает возникновение таких языковых явлений, как полисемия, паронимия и омонимия. Необходимо было решить, какие значения будут даны студентам, а какие - нет. Для большей ясности определение обычно не содержит более трех значений. На этапе тестирования студенты получали новую информацию 
еще об одном значении слова, которого они до этого момента не знали. В этой части упражнения учащиеся легко могут перевести омоним на свой родной язык.

\section{2. Соедините слова с их значением (к определениям впишите номер слова):} Таблица № 1

\begin{tabular}{|l|l|l|l|}
\hline 1 & Ваза & A & $\begin{array}{l}\text { двигать из стороны в сторону (хвостом, бёдрами и } \\
\text { т.п.) }\end{array}$ \\
\hline 2 & Верный & Б & $\begin{array}{l}\text { единица исчисления времени, равная семи дням, от } \\
\text { понедельника до воскресенья включительно }\end{array}$ \\
\hline 3 & Вилять & B & $\begin{array}{l}\text { 1. ступить, стать ногой, лапой на кого-, что-л.; } 2 . \\
\text { начаться, настать. }\end{array}$ \\
\hline 4 & Наступить & $\Gamma$ & $\begin{array}{l}\text { сосуд декоративного или бытового назначения для } \\
\text { фруктов, цветов }\end{array}$ \\
\hline 5 & Неделя & Д & $\begin{array}{l}\text { 1. соответствующий истине, действительности; } \\
\text { 2. не вызывающий сомнения в своей надёжности; } \\
\text { несомненный, очевидный }\end{array}$ \\
\hline
\end{tabular}

Третий вид упражнений - перевод на родной язык. Для того, чтобы студенты четко осознавали различия, в первом предложении не использовалась фраза «ваза с цветами» или во втором - «верный друг». При многозначных лексемах было больше предложений на перевод, чтобы в каждом реализовывалось данное значение.

Переведите следующие предложения на словацкий язык, обращая особое внимание на выделенные слова:

1. Мама купила декоративную вазу для фруктов.

2. Самое верное средство от избыточного веса - активное движение и здоровое питание.

3. Если собака виляет хвостом, это не всегда означает, что она радуется. // Дорога виляла то вверх, то вниз, то вправо, то влево. // Слушай, Дима, не виляй, говори правду.

4. Никто не ожидал, что после так тёплой осени внезапно наступит столь жестокая зима.

5. Через две недели мы переселимся в другой город.

Следующий шаг - прямой перевод. У студентов обычно не возникает проблем с основным значением лексемы и ее переводом. Со второстепенными значениями проблемы, как правило, имеют место быть.

\section{3. Переведите на словацкий язык:}

ваза - верный - вилять - наступить - неделя

В следующей части главы иллюстрируется противоположная процедура - работа со словацким омонимичным выражением. Процедура такая же, как и во втором упражнении. Смысл заключается в соединении лексемы с ее значениями в родном языке. Студенты не всегда осознавали многозначность словацких единиц и их возможные переводы на русский язык. Именно на это было ориентировано данное упражнение, призванное напомнить им о значении этого слова. Опять же, даже в этой части мы не работали со всеми значениями словацких единиц. Лишь наиболее важные из них были включены в определения. Это упражнение обычно содержало и новую лексику, с помощью которой студенты пополняли свой словарный запас.

4. Соедините слова с их значением:

Таблица № 2

\begin{tabular}{l|l|l|l}
\hline 1 & Váza & A & вылить, перелить откуда-л. (какую-л. жидкость)
\end{tabular}




\begin{tabular}{|l|l|l|l|}
\hline 2 & Verný & Б & $\begin{array}{l}\text { сосуд декоративного или бытового назначения для } \\
\text { фруктов, цветов и т.п. }\end{array}$ \\
\hline 3 & Vyliat' & B & $\begin{array}{l}\text { начать, приняться делать что-нибудь, стать } \\
\text { членом коллектива в работе, смене, армии и т.п. }\end{array}$ \\
\hline 4 & Nastúpit' & $\Gamma$ & $\begin{array}{l}\text { такой, который не предаст, не подведёт кого-л., не } \\
\text { изменит кому-л.; преданный, надёжный }\end{array}$ \\
\hline 5 & Nedel'a & Д & $\begin{array}{l}\text { седьмой день недели, следующий за субботой } \\
\text { (обычно день отдыха) }\end{array}$ \\
\hline
\end{tabular}

Далее в главе представлены упражнения по принципу: родной язык - целевой язык.

\section{5. Переведите на русский язык:}

váza - verný - vyliat' - nastúpit' - nedel'a

Третье упражнение было направлено на перевод и актуализацию различных значений русских омонимов. В этом упражнении при переводе предложений на словацкий использовались омонимы из предыдущего упражнения.

6. Переведите следующие предложения на словацкий язык, обращая особое внимание на выделенные слова:

1. На столе лежала ваза под фрукты.

2. Без верного друга не сва узнаешь, какие ошибки совершаешь.

3. Нужно будет слить воду из бассейна.

4. Мне сказали, что меня приняли на работу, и я смогу приступить уже на следующей неделе.

5. По воскресеньям семья собирается за большим столом и обедает вместе.

Далее следует более сложная часть, когда впервые в этой главе мы работаем с обеими системами одновременно. Сложно концентрироваться и сразу же реагировать на переключение с системы на систему. В конечном счете это ускоряет реакцию студентов при переключении систем, что особенно полезно для синхронного перевода.

\section{7. Переведите в быстром темпе:}

ваза - váza, верный - verný, вилять - vyliat', наступить - nastúpit', неделя - nedel'a

Ниже приведено еще одно упражнение для перевода на русский язык, при этом порядок не случаен. Например, в первой паре фраз для перевода мы сначала использовали misa, а во второй - váza, чтобы задача не была слишком простой. Для этой части упражнения были выбраны фразы не очень сложные для перевода, за исключением омонимов.

\section{8. Переведите:}

misa s ovocím - váza s kvetmi, hodnoverné informácie - verný spoločník, vrtiet' chvostom - vyliat' mlieko, prichádza jeseň - stupit' na hrable, niekol'ko týždňov - pokojná nedel'a

Последнее упражнение лекции - перевод целых предложений. На материале предыдущих упражнений студенты несколько раз имели возможность выучить новые омонимичные выражения. Это упражнение, с точки зрения самих омонимов, было освоено без особых трудностей.

\section{9. Переведите:}

Na stole stála váza plná slnečníc.

Verný priatel' táa nikdy nezradí.

Pri kúpaní sa v mori chlapec stupil na morského ježka.

Prišla jar a sneh sa začal topit'.

Pracujem na tom už celý týždeň. 
Концепция данного учебника была проверена в течение одного года и постепенно совершенствовалась. Во время работы с материалом на занятиях, а также после них, мы получали ценные отзывы студентов, проводили переоценку и доработку замечаний. Целью данной статьи было объяснить феномен межъязыковой интерференции и омонимии, а также представить учебник и различные типы упражнений, которые направлены на устранение негативного переноса, вызванного межъязыковой омонимией, и тем самым способствуют правильной идентификации и их передаче на иностранном языке у студентов.

\section{Использованная литература/ References}

\section{Печатные источники:}

BROWN, H. D: 2014. Principles of Language Learning and Teaching. London: Pearson Education, 2014. 416 pp. ISBN: 0133041948

DULEBOVÁ, I. - CINGEROVÁ, N. 2017: Ruské lingvoreálie. Bratislava: Univerzita Komenského v Bratislave, 2017. 274 c. ISBN 978-80-223-4431-9

FILIPEC, J. - ČERMÁK, J. 1985: Česká lexikologie. Praha: Academia, nakladatelství Československé akademie věd, 1985. 284 c. ISBN 8677-21-011-86

ONDRUS, P. - HORECKÝ, J. - FURDÍK, J. 1980: Súčasný slovenský spisovný jazyk: Lexikológia, Bratislava Slovenské pedagogické nakl., 1980. ISBN 22-130-131

VAŇKO, J. 2004: Slovinsko-slovenská interlingválna homonymia. In Slavia, 73, 1, pp. 59-70, ISBN 80-8050-957-3 КОНДРАШОВ, Н.А. - КУБИК, М.: Русский язык глазами слависта. Русский язык глазами слависта-лингвиста. Praha: Státni pedagogické nakladatelství, 1977. c. 157-250.

КРЕТОВ, А.А. - ВОЕВУДСКАЯ, О.М. - МЕРКУЛОВА, И.А - ТИПОВ, В.Т.: Единство Европы по данным лексики [Монография]. Воронеж: Издательский дом ВГУ, 2015. 415 с.

КУБИК, М. - КОНДРАШОВ, Н.А. 1977: Русский язык глазами лингвиста-слависта, Praha: Státní pedagogické nakladatelství, 1977. C. $157-250$

\section{Онлайн-источники:}

КУЗНЕЦОВ, С. А. - гл. ред. 2014: Большой толковый словарь русского языка. [Электронный ресурс] URL: http://gramota.ru/ (дата обращения: 16.04.2020)

ДАННАЯ СТАТЬЯ ПОДГОТОВЛЕНА В РAMКАХ ПРОЕКTA KEGA Č. 021UCM-4/2020 S NÁZVOM TVORBA UČEBNÍC PRE RUSKOSLOVENSKÉ SEKCIE BILINGVÁLNYCH A SLOVANSKÝCH GYMNÁZIÍ.

\section{Профиль автора:}

Лукаш Гаярски, старший преподаватель, PhDr., PhD.

Научные интересы: омонимия, паремиология, аксиологическая лексика

e-mail: lukas.gajarsky@ucm.sk

Место работы: Университет им. св. Кирилла и Мефодия в Трнаве, пл. Й. Герду 2, 917 01, Трнава, Словакия

\section{Author`s profile:}

Lukáš, Gajarský, senior lecturer, PhDr., PhD.

Interests: homonymy, paremiology, axiological linguistics

e-mail:lukas.gajarsky@ucm.sk

Place of work: University of Ss. Cyril and Methodius in Trnava, Nám. J. Herdu 2, 91701 Trnava, Slovakia 